\title{
Dorsal Spinocerebellar Tract Neurons in the Chronic Intact Cat during Wakefulness and Sleep: Analysis of Spontaneous Spike Activity
}

\author{
Peter J. Soja, Miguel C. Fragoso, Brian E. Cairns, and William-G. Jia \\ Division of Pharmacology and Toxicology, Faculty of Pharmaceutical Sciences, University of British Columbia, Vancouver, \\ British Columbia, Canada V6T $1 Z 3$
}

\begin{abstract}
Relatively little is known about the transmission of ascending sensory information from lumbar levels across the behavioral states of sleep and wakefulness. The present study used extracellular recording methods in chronically instrumented intact behaving cats to monitor the activity of lumbar dorsal spinocerebellar tract (DSCT) neurons within Clarke's column during the states of wakefulness, quiet sleep, and active sleep. Clarke's column DSCT neurons were identified using antidromic identification and retrograde labeling techniques. The spontaneous spike rate and interspike interval data of DSCT neurons were quantified as a function of behavioral state. During wakefulness and quiet sleep, the spike rate of DSCT neurons was stable, and interspike interval histograms (ISIH) indicated a relatively high degree of regularity in DSCT neuronal spike train patterns. In contrast, during active sleep there was a marked reduction in the ongoing spike rate in a vast majority of
\end{abstract}

The dorsal spinocerebellar tract (DSCT) is one of the most intensively investigated ascending lumbar sensory pathways. Electrophysiological and anatomical studies have shown that in the midlumbar segments of the spinal cord at least two DSCT neuronal pathways can be differentiated: those DSCT neurons that are located within Clarke's nucleus (Mann, 1973; Oscarsson, 1973; Burke and Rudomin, 1977; Matsushita et al., 1979; Bloedel and Courville, 1981; Walmsley, 1991), and those situated within the dorsal horn gray matter, dorsal and lateral to Clarke's column (Edgley and Gallimore, 1988; Edgley and Jankowska, 1988). Clarke's column contains large cell bodies with axons that project to the ipsilateral anterior lobe of the cerebellum. The information conveyed by Clarke's column DSCT neurons is proprioceptive in nature, emanating primarily from group Ia and Ib afferents (Eccles et al., 1961; Kuno et al., 1973; Walmsley, 1991). In addition, exteroceptive inputs from cutaneous sources also have been described for Clarke's column DSCT neurons (Kuno et al., 1973; Mann, 1973).

Clarke's column DSC'I' neurons often have been compared with lumbar motoneurons in terms of their anatomical, physiological, and pharmacological charactcristics, although most of

\footnotetext{
Received Aug. 30, 1995; revised Oct. 20, 1995; accepted Oct. 25, 1995

This work was supported by grants from the Medical Research Council of Canada. Correspondence should be addressed to Dr. Peter J. Soja, Faculty of Pharmaceutical Sciences, University of British Columbia, 2146. East Mall, Vancouver, British Columbia, Canada V6T 123.

Dr. Jia's present address: Departments of Ophthalmology and Surgery, Faculty of Medicine, University of British Columbia, 2550 Willow Street, Vancouver, British Columbia, Canada V5Z 3N9.

Copyright (C) 1996 Society for Neuroscience $0270-6474 / 96 / 161260-13 \$ 05.00 / 0$
}

cells tested. The magnitude of change in ISIHs and interspike interval data during active sleep depended in part on whether the reduction in cell firing was maintained or periodic throughout active sleep. Further suppression of spontaneous activity also was observed during intense rapid-eye-movement episodes of active sleep that were associated with clustered pontogeniculo-occipital wave and muscular twitches and jerks. After re-awakening, spontaneous spike activity of Clarke's column DSCT neurons resembled that recorded during previous episodes of wakefulness. These data provide evidence that ascending proprioceptive and exteroceptive sensory transmission through Clarke's column is diminished during the behavioral state of active sleep.

Key words: action potential; antidromic; behavioral state; dorsal spinocerebellar tract; scnsory; slecp; spinal cord these comparisons by necessity have been conducted in "acute" animal preparations (Mann, 1973; Burke and Rudomin, 1977; Walmsley, 1991). Consequently, very little is known about the discharge characteristics of DSCT neurons during naturally occurring behaviors or bchavioral states such as wakefulncss and active sleep. Given that DSCT neurons receive a substantial afferent input of muscle spindle origin, which is known to be suppressed during the atonia of active sleep (Kubota et al., 1967), it can be predicted that synaptic transmission through the DSCT also is suppressed during this state compared with other states such as wakefulness or quiet sleep. However, the only studies performed on sensory transmission through the DSCT are the indirect field-potential studies of Carli et a1. (1967b), who reported that peripheral nerve-evoked mass potentials recorded in the cerebellum were suppressed only during the phasic rapid-eye-movement (REM) episodes of active sleep. This finding suggests that individual DSCT neurons undergo modulatory influences during active sleep.

Accordingly, the present study was performed to investigate this possibility. Specifically, we recorded extracellularly from DSCT ncurons during the behavioral states of wakefulness, quiet sleep, and transition into and throughout active sleep. The results are discussed with respect to the activity of these cells during wakefulness and sleep versus during the anesthetic state of previous studies. Finally, the possible mechanisms and significance underlying the changes observed during active sleep are presented.

Portions of this work have been presented previously (Soja et al., 1994, 1995a). 


\section{MATERIALS AND METHODS}

Surgical implant procedures. Five adult cats were prepared for chronic recording of DSCT neurons. Detailed descriptions of the surgical implantation of head and lumbar restraint devices, postsurgical recovery procedures, and program for gradual adaptation of chronically instrumented cats to head and lumbar restraint appear elsewhere (Soja et al., 1995b). All surgical implant and chronic restraint procedures performed met national and international regulatory statutes.

Electrophysiological recording and antidromic identification procedures. Instrumented cats were placed carefully in the recording setup and allowed a $1 \mathrm{hr}$ acclimation period before unit recording sessions began. Recording sessions lasted $4-5 \mathrm{hr} / \mathrm{d}$ for 3 consecutive days. Behavioral states were defined based on cortical electroencephalogram (EEG), electro-oculogram (EOG), pontogeniculo-occipital ( $\mathrm{PGO}$ ) wave, and neck electromyogram (EMG) activities using criteria reported previously (Ursin and Sterman, 1981; Soja et al., 1991, 1993, 1995b,c).

Glass micropipettes containing a carbon fiber (Armstrong-James and Millar, 1979) that were back-filled with $4 \mathrm{M} \mathrm{NaCl}$ were used to record from L3 spinal cord neuronal elements using an alternating current (AC)-coupled amplifier (model 1800, A-M Systems, Everett, WA). Amplified signals $(1000 \times$, bandpass, $0.3-10 \mathrm{kHz})$ were routed to a window discriminator, rate counter (Digitimer, Cambridge, UK), and oscilloscope. Recording electrodes were lowered slowly into tracks beginning $0.2-0.6 \mathrm{~mm}$ lateral to the midline of the L3 spinal cord. Search stimuli applied to the sciatic nerve aided in locating cells. Sciatic nerve-evoked orthodromic field potentials corresponding to those described by Edgley and Jankowska (1987) were used to demarcate more dorsal and lateral portions of the dorsal horn gray matter.

Before recording spinal cord neuronal activity, a cerebellar stimulating electrode (A-M Systems, catalog no. 5755, 5-8 M $\Omega, A C$ ) was lowered stereotaxically into tracks located $1-2 \mathrm{~mm}$ anterior to the primary fissurc (sterotaxic coordinates: $4-5 \mathrm{~mm}$ posterior and $3.5-4.0 \mathrm{~mm}$ lateral to the midline at a final depth of $10-13 \mathrm{~mm}$ below the cerebellar surface). Cerebellar electrode trajectories were directed at lobules III and IV using an angle of $36^{\circ}$ posterior to the vertical plane.

Criteria for antidromic activation included constant-latency spikes evoked by consecutive low-intensity monopolar stimuli $(0.2 \mathrm{msec}, 0.5 \mathrm{~Hz}$, $70-540 \mu \mathrm{A}$ ), the ability to follow a short train of high-frequency stimuli faithfully, and collision with spontaneous or peripheral nerve-evoked action potentials (Lipski, 1981). Antidromically activated neurons were considered to comprise the DSCT if they could be isolated either from an antidromic field potential evoked by cerebellar stimuli (Soja et al., 1995b) or at in situ recording depths corresponding to Clarke's nucleus (Fig. $3 B, C)$. DSCT neurons are characterized further by their ongoing spike activity, with individual cells displiaying rather large-amplitude $(0.5-2.5$ $\mathrm{mV})$ unitary spike potentials. Finally, DSCT neurons respond to shortlatency (2-5 msec) monosynaptic (Oscarsson, 1973; Knox et al., 1977) and longer-latency ( $>5 \mathrm{msec}$ ) oligosynaptic inputs from low-threshold afferent fibers. For each neuron, identification procedures were performed first, and then spontaneous spike activity was monitored across the sleep-wake cycle.

Data analyses. A microcomputer (Macintosh Quadra 650, Apple Computer, Cupertino, C.A) equipped with software for spike acquisition and analyses (SPIKE 2-1401plus, Cambridge Electronic Design, Cambridge, UK) was used to quantify neuronal data. A spike-sorting subroutine was used to verify that the sampled spike data were recorded from the same DSCT neuron across all behavioral states. Tolerance criteria were set to ensure that accepted spikes did not deviate by $10 \%$ in peak-to-peak spike amplitude. The average spontaneous firing frequency (spikes/sec) was calculated for each neuron using minimum 1 min epochs of spike activity.

Data obtained during wakefulness served as control for comparison with data obtained during quiet sleep, the middle portion of active sleep, and the subsequent episode of wakefulness. For spike rate, differences between control and test (quiet sleep, transition, and active sleep) states were analyzed for statistical significance using repeated-measures ANOVA (Statistica 4.1, Statsoft, Tulsa, OK) with $\alpha$ set at 0.05 .

Interspike interval histograms (ISIHs) were compiled for the same $1 \mathrm{~min}$ epochs used for determining spike rate during sleep and waking states. The following statistical parameters were used to describe spike interval data: median, inner quartile range, cocfficient of dispersion $(\mathrm{CD} ; \mathrm{CD}=$ variance/ mean interval), and coefficient of variation ( $\mathrm{CV} ; \mathrm{CV}=$ standard deviation/ mean interval). Statistical parameters describing the ISIHs of DSCT neurons were expressed as group mean values $\pm \mathrm{SE}$. Finally, correlations between various DSCT parameters (i.e., conduction velocity, spike rate) were tested using the Spearman-Rank correlation test.
Terminal procedures. After all recording sessions and under general anesthesia, the cerebellum and spinal cord were marked by electrolytic lesions made by passing $50 \mu \mathrm{A}$ of anodal current for $15 \mathrm{sec}$ through the tip of the electrodes. In two cats, the stimulation sites in the cerebellum were injected with $10 \mu \mathrm{l}$ of cholera toxin B subunit conjugated with colloidal gold (List Biological, Campbell, CA). This retrograde marker was injected at stereotaxic coordinates corresponding to those sites where low-threshold stimuli antidromically activated individual DSCT neurons (see Results). Approximately $36 \mathrm{hr}$ later, cats were killed with a fatal dose of sodium pentobarbital (Euthanyl, $0.5 \mathrm{mg} / \mathrm{kg}$, i.v.) and perfused with

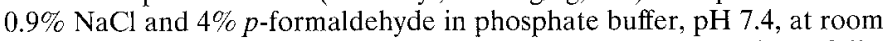
temperaturc. The cntirc brain and spinal cord were removed carefully, and the conduction distances from the recording sites in the L3 spinal cord to the cerebellum were measured. The brain and spinal cord were cut into blocks and post-fixed with the same fixative at $4^{\circ} \mathrm{C}$ for $24 \mathrm{hr}$. Additionally, both the cerebellum and the spinal cord were cut into 60 $\mu \mathrm{m}$ sections with a vibratome. The colloidal gold labeling in DSCT neurons in L3 segments was enhanced with a silver-intensifying reagent (IntenSEM, Amersham, Buckinghamshire, UK) for $45 \mathrm{~min}$ at room temperature. The coronal spinal L3 cord sections, as well as sagittal sections of the pontine-medullary brainstem and cerebellum corresponding to stimulation sites, were counterstained with neutral red.

\section{RESULTS}

Fifty cells were recorded in the L3 spinal cord segment that were identified antidromically as DSCT neurons and monitored during sleep and wakefulness. Recording depths in situ ranged from 1600 to $3200 \mu \mathrm{m}$ below the surface of the spinal cord. Recording conditions for individual DSCT neurons were vcry stable and often exceeded 3 hr (Soja et al., 1995b). However, for data presented here, the sampling period for each neuron was limited to a minimum of one complete cycle of wakefulness, quiet sleep, active sleep, and subsequent re-awakening. The average time the cats spent in active sleep during recording sessions was $4.7 \pm 0.3$ (SE, here and below) min (range $1.6-10.2 ; n=50$ ).

\section{DSCT neurons: general characteristics}

Low-intensity search stimuli delivered to the anterior cerebellum were effective in activating L3 neurons in the chronic preparation. Minor adjustments of position $(100-200 \mu \mathrm{m})$ of the cerebellar stimulation electrode were effective in lowering the threshold for antidromic invasion markedly; however, this was not determined systematically for every cell presented in this study. Nevertheless, the mean threshold stimulus measured for 50 cells was $245.9 \pm$ $19.5 \mu \mathrm{A}$ (range $70-540$ ).

Standard criteria for identifying L3 spinal cord neurons as DSCT neurons included a constant latency spike after cerebellar stimuli, the ability of the recorded neuron to follow highfrequency stimulus trains, and collision between orthodromically and antidromically propagated spikes (Lipski, 1981; Soja et al., 1995b). An example of a neuron meeting each of these criteria is illustrated in Figure 1. Consecutive antidromically generated spikes of DSCT cells demonstrated constant latency and, as shown in Figure $1 A$, were superimposable. Antidromic action potentials also followed short-duration threshold stimulus trains (2-6 pulses) delivered at $1 \mathrm{~Hz}$. The interpulse intervals within the train were varied between 1.25 and $3.0 \mathrm{msec}$, which corresponds to frequencies of 800 and $333 \mathrm{~Hz}$, respectively (Fig. $1 B$ ). Highfrequency following using longer stimulus trains consisting of up to six pulses often was demonstrated for most other DSCT neurons in this report (see Fig. 3 in Soja ct al., 1995b). Such stimuli, when applied at threshold intensities, never aroused the animal and did not interfere with the animal's normal oscillations between wakefulness and sleep.

Collision between orthodromically and antidromically propa- 


\section{A. Constant Latency C. Collision - Spontaneous D. Collision - Evoked}

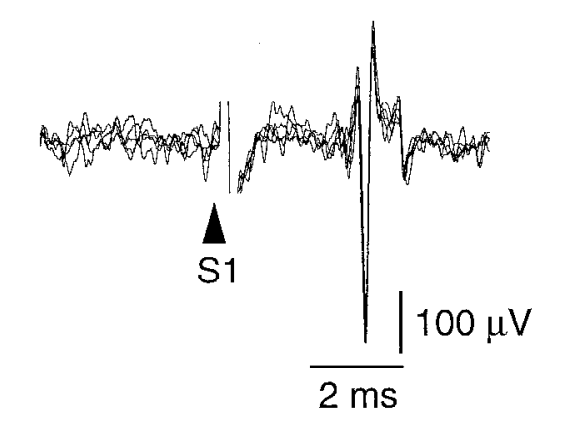

\section{B. High Frequency Following $(500 \mathrm{~Hz})$}

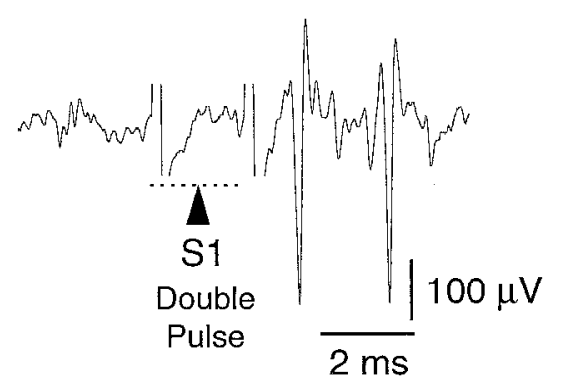

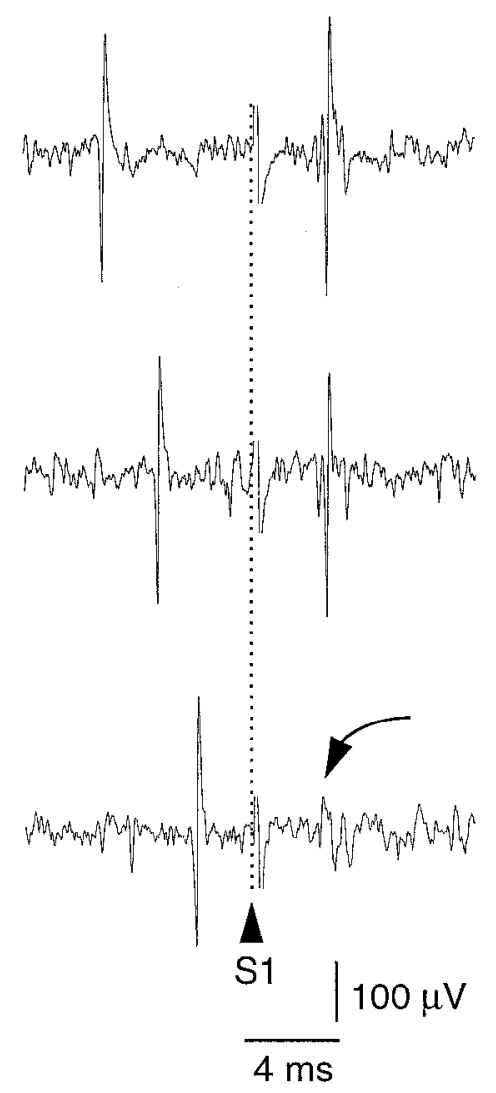
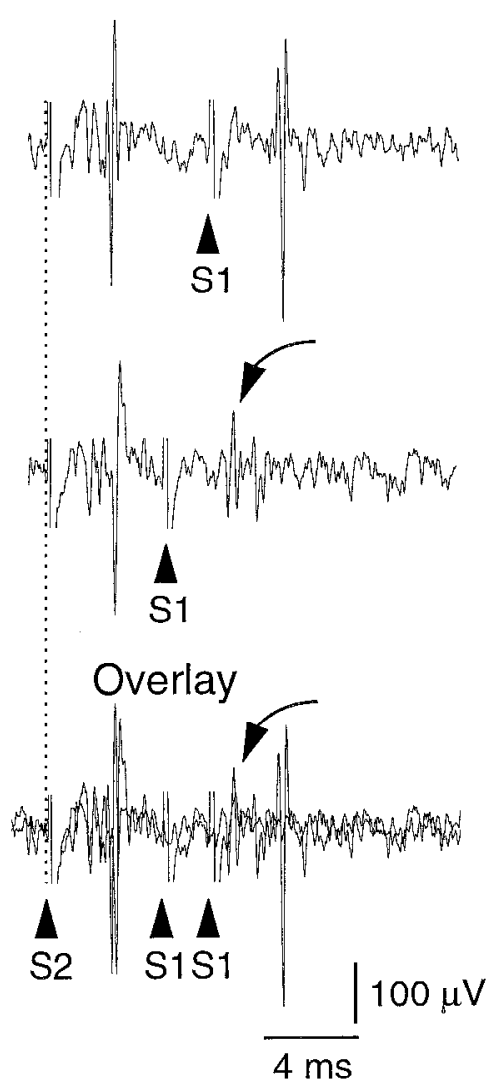

Figure 1. Electrophysiological criteria for identifying DSCT neurons in the chronic unanesthetized cat preparation. $A$, Low-intensity stimulation of the anterior lobe of the cerebellum $\left(S^{\prime} I\right)$ evoked an action potential at constant latency of 2.9 msec. I'hree consecutive oscilloscope sweeps indicate that the evoked spikes are superimposable, indicating a lack of "jitter" in the latency of spike discharge. $B$, The same cell as in $A$ responded faithfully to a short-duration, high-frequency stimulus train $(500 \mathrm{~Hz})$. In this particular cell, collision between orthodromically and antidromically propagated action potentials also was demonstrated using spontaneously occurring $(C)$ and peripheral nerve-evoked $(D)$ spike activity, $C$, Three consecutive oscilloscope sweeps are presented such that the antidromic stimuli are aligned in the center of each trace. The antidromically propagated spike is evident in the top two traces in C. Collision of the antidromic spike occurs in the bottom trace in $C$ when a spontaneous action potential occurs within the critical period for this cell. The top trace in $D$ shows the same DSCT neuron's consistent response to sciatic nerve stimulation $(S 2)$ followed $3.4 \mathrm{msec}$ later by cerebellar stimulation $(S 7)$. In this case, the traces are aligned with respect to the sciatic nerve stimulus artifacts. Note that collision occurs when the interval between sciatic nerve and cerebellar stimuli is reduced to 2.5 msec $(D$, middle trace $)$. The bottom trace in $D$ represents the composite overlay of the first two traces. The curved arrows in $C$ and $D$ denote the point time in which the antidromically propagated action potentials should have occurred. The conduction velocity of this DSCT neuron was estimated at $97 \mathrm{~m} / \mathrm{sec}$ (antidromic stimulus: $260 \mu \mathrm{A}, 0.2 \mathrm{misec}, 1.0 \mathrm{~Hz}$; sciatic nerve stimulus: $235 \mu \mathrm{A}, 0.05 \mathrm{msec}, 1.0 \mathrm{~Hz}$ ).

gated action potentials is considered to be the most robust criterion of antidromicity and is essential if one is identifying the axonal destination of recorded lumbar sensory neurons in the chronic cat preparation (Soja et al., 1995b). The ongoing spike activity of DSCT neurons in the chronic cat preparation provides ideal conditions for demonstrating spontaneous collision, as illustrated in Figure $1 C$. Therefore, in the present study, collision consisted of two types-spontaneous and evoked. Collision between spikes propagated antidromically and spikes generated orthodromically also was possible and was achieved most easily in cells in which there was a consistent short-latency action potential evoked by peripheral nerve stimulation (Fig. $1 D$ ) (see Soja et al., 1995b). However, in the present study the spontaneous type of collision was demonstrated easily for every cell.

The average antidromic latency for spike generation measured from the beginning of the stimulus artifact to the initiation of the action potential measured $3.5 \pm 0.1 \mathrm{msec}$ (range 2.7-5.6). Esti- mates of DSCT neuron conduction velocity were based on postfixation conduction distances and measured $81.1 \pm 2.1 \mathrm{~m} / \mathrm{sec}$ (range 47.8-104.4). The distribution of 50 DSCT neuron antidromic latencies and conduction velocities is illustrated in Figure 2 and corroborates values reported in acute anesthetized preparations (Iundherg, 1964; Mann, 1973; Burke and Rudomin, 1977; Bloedel and Courville, 1981).

After antidromic identification, each neuron was tested for its response to low-threshold stimulation of the ipsilateral sciatic nerve. Threshold stimuli (276 $\pm 15.9 \mu \mathrm{A}$; range $160-450)$ applied to the sciatic nerve evoked a short-latency monosynaptic response (Fig. $1 D$ ) characterized by a single action potential or by two action potentials (latency $3.4 \pm 0.15 \mathrm{msec}$; range $2.0-5.0$ ), which is consistent with previous observations obtained in acute anesthetized animal preparations (Lundberg, 1964; Oscarrson, 1973; Knox et al., 1977). Stimuli applied to the sciatic nerve also evoked polysynaptic responses that were characterized by a short burst of 

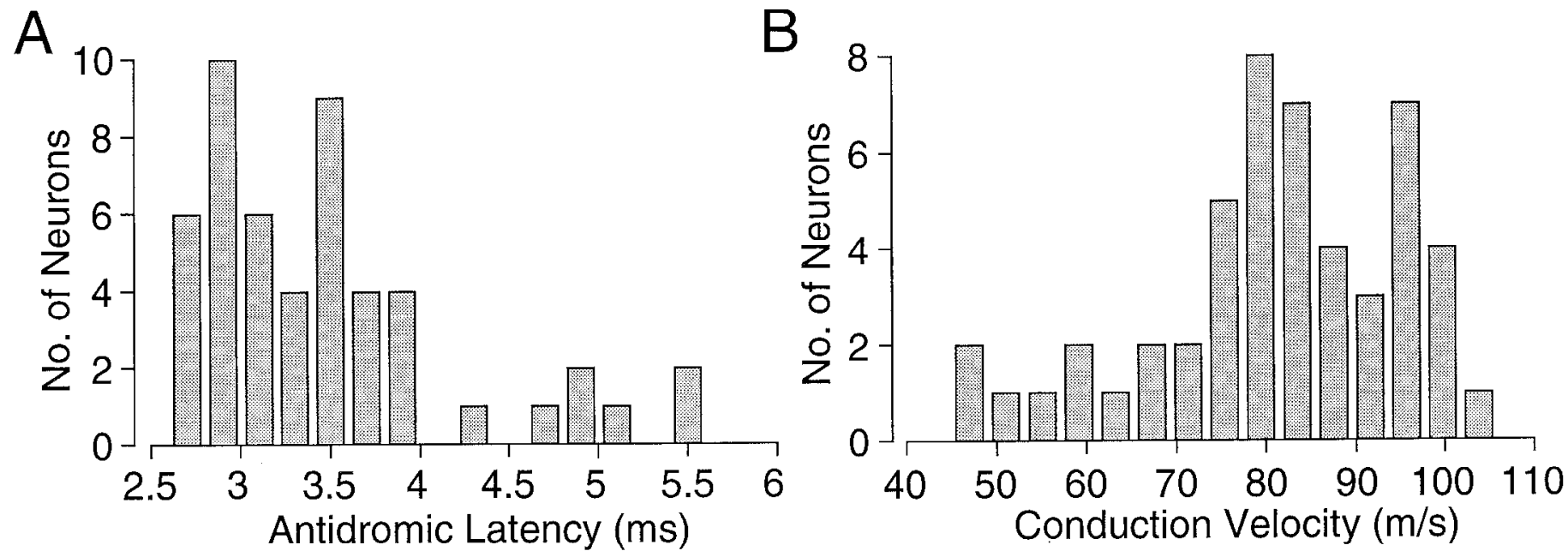

Figure 2. A, Distribution of antidromic latencies; $B$, estimates of DSCT neuron axonal conduction velocity in the chronic unanesthetized cat preparation. The mean \pm SEM antidromic latency and conduction velocity of 50 DSCT neurons measured $3.5 \pm 0.1 \mathrm{msec}$ and $81 \pm 2.1 \mathrm{~m} / \mathrm{sec}$, respectively.

spikes (3-6) with an average latency of $18.1 \pm 3.5 \mathrm{msec}$ (range 7-40). Detailed analyses of the DSCT neuronal responses to consecutive volleys delivered to the sciatic nerve across wakefulness and sleep will be presented elsewhere.

\section{Anatomical location of DSCT neurons in the chronic cat preparation}

Our sample of cells reported here comes entirely from electrode tracts directed $0.2-0.6 \mathrm{~mm}$ lateral to the midportion of the dorsal columns and at in situ depths corresponding to micromanipulator readings between $\sim 1600$ and $3200 \mu \mathrm{m}$. Actual micromanipulator depth readings in the chronic preparation over the course of the animal's recording lifespan are misleading. Anatomical studies have indicated that Clarke's column DSCT neurons are located at depths ranging from $\sim 1500$ to $2000 \mu \mathrm{m}$ (Randic et al., 1981; Houchin et al., 1983; Walmsley and Nicol, 1990). To confirm that our antidromically activated neurons were located within Clarke's column compared with more dorsolaterally situated DSCT neurons that also are present in midlumbar spinal cord segments (Edgley and Gallimore, 1988), cholera toxin B subunit conjugated with colloidal gold was microinjected in two separate cats at the exact stereotaxic coordinates where antidromic stimuli "backfired" spinal cord cells. This procedure yielded retrogradely labeled DSCT neurons located entirely within Clarke's nucleus at spinal cord depths ranging from $\sim 850$ to $1200 \mu \mathrm{m}$ after fixation (Fig. $3 B, C$ ). The discrepancy between our in situ micromanipulator depth readings and post-fixation labeling results likely is at tributable to multiple factors including tissue shrinkage, inherent dead space in pneumatic microdrive slave cylinder, and false zeros caused by the presence of CSF produced on the cord surface, despite routine efforts to minimize the impact of the latter two factors.

Nevertheless, our anatomical and physiological findings, together with previous neuroanatomical data (Grant and Xu, 1988; Walmsley and Nicol, 1990), indicate that our recordings emanated from large cell bodies located entirely within Clarke's column. In addition, they highlight the possible hazards of relying only on micromanipulator depth readings in assigning unidentified cells recorded in the chronic preparation as belonging to a specific dorsal horn lamina or ascending sensory pathway.

\section{Spontaneous spike activity during wakefulness and quiet sleep}

Clarke's column DSCT neurons in the chronic unancsthetized cat demonstrate spontaneous spike activity (Soja et al., 1994, 1995a,b). During wakefulness and quiet sleep, the occasional postural adjustment does occur, causing reversible phasic increases or decreases in DSCT neuronal spike activity. However, the association between firing rate and different postural positions was not assessed in this study. Nevertheless, the frequency of occurrence of such movements is very low and does not interfere with the collection of stable baseline data (Soja et al., 1995b). During quiet wakefulness, a state in which little or no postural movements occur and that is also characterized by a desynchronized cortical EEG pattern, tonic EMG activity, and sparse or nn PGO and EOG activity, the average spontaneous discharge rate of all 50 DSCT neurons measured $17.6 \pm 1.3$ spikes/sec (range 3.5-45.7). There was no correlation between spontaneous spike discharge rate of DSCT neurons during the state of wakefulness and their axonal conduction velocity $(r=0.07, p>0.05)$, substantiating previous studies performed in the acute anesthetized cat preparation (Knox et al., 1977). An example of the spontaneous spike discharge rate of a DSCT neuron during wakefulness is illustrated in Figure $4 \boldsymbol{A}$.

The behavioral state of quiet sleep is characterized by a large-amplitude-synchronized slow-wave EEG pattern, relatively moderate EMG activity, and little or no EOG and PGO wave activity (Fig. $4 A$ ). The group mean spontaneous spike rate for 50 DSCT neurons measured $16.9 \pm 1.3 \mathrm{spikes} / \mathrm{sec}$ (range $1.7-44.6, p>0.05$ ). The stable baseline in spike activity of a typical DSCT neuron recorded in the chronically instrumented cat during wakefulness and quiet sleep is illustrated in Figure $4 A$. The scattergram in Figure $4 B$ indicates that for every cell, the firing rate during wakefulness and quiet sleep was not different $(r=0.952, p<0.05)$. Thus, the ongoing spike rate of DSCT neurons does not differ between the behavioral states of wakefulness and quiet sleep. 

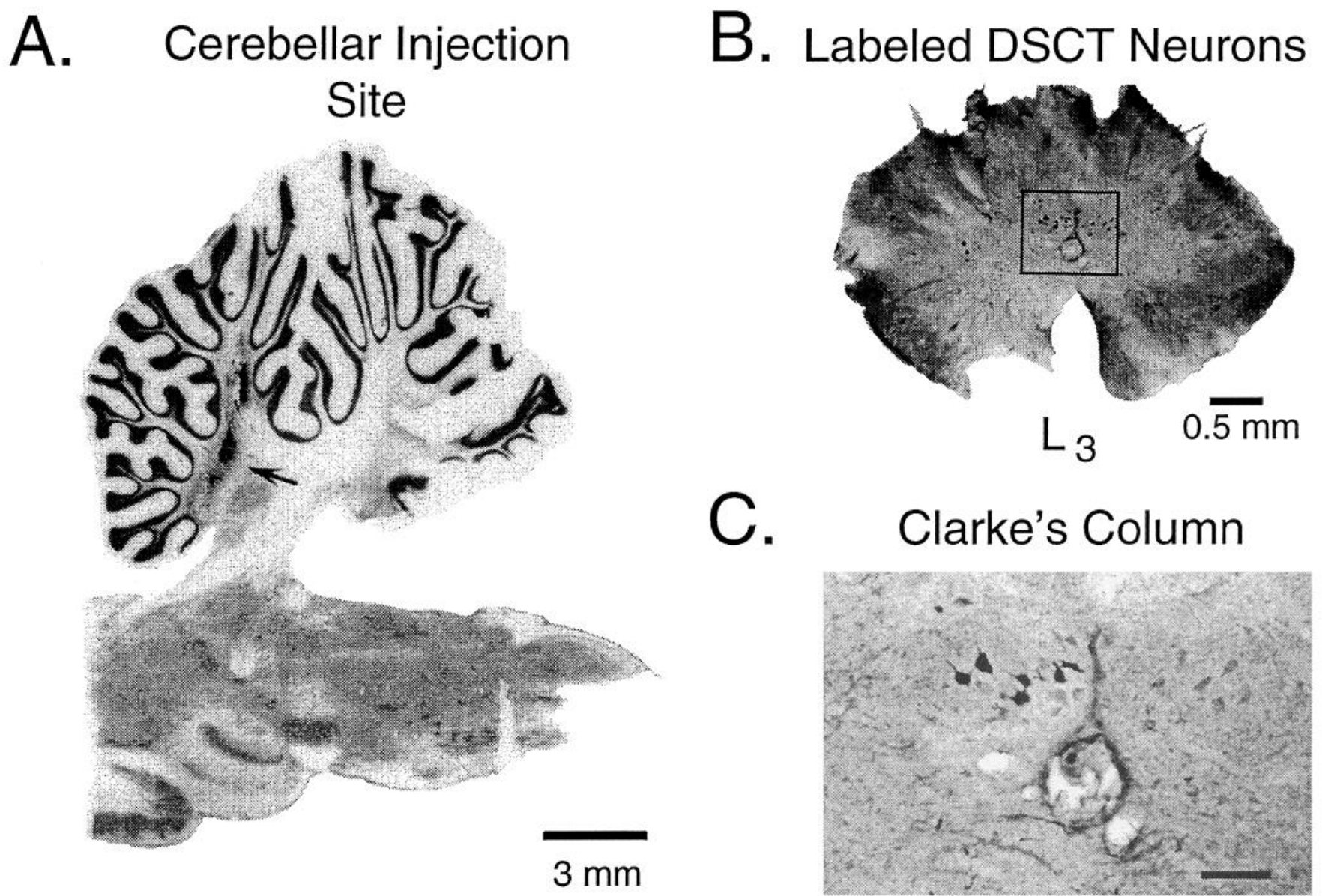

\section{Clarke's Column}

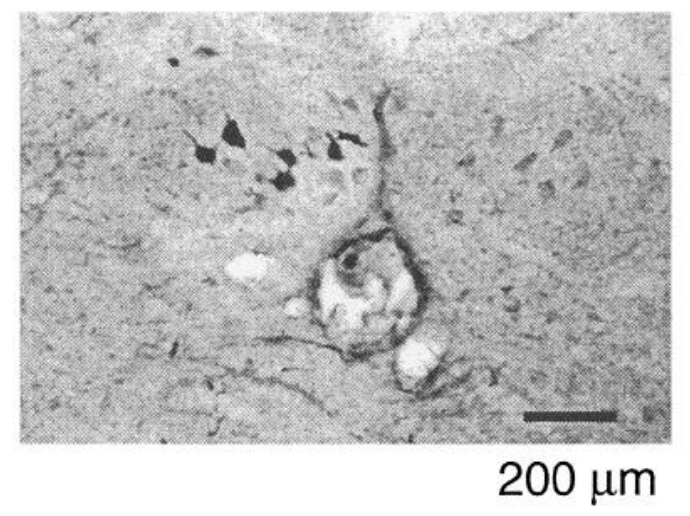

Figure 3. Anatomical visualization of the DSCT neurons recorded in the chronic cat. Ten microliters of cholera toxin B subunit conjugated with colloidal gold were microinjected at stereotaxic coordinates (stereotaxic coordinates: posterior, 5 ; lateral, $3.5 ; 11$ mm below the cerebellar surface) where search stimuli also were effective in antidromically activating Clarke's column DSCT neurons in the L3 spinal cord segment (see Fig. 1). The reaction product in $A$ (arrow) represents the site of microinjection. Coronal sections of the L3 spinal cord demonstrated retrogradely labeled DSCT neurons confined to Clarke's column ipsilateral to the site of microinjection (boxed area in $B$ ). The boxed area is magnified in $C$ to illustrate clearly the large somata of labeled Clarke's column DSCT neurons. Clustering of gold-labeled DSCT neurons is evident in $C$.

\section{Spontaneous activity during transition into and throughout active sleep}

Large-amplitude primary PGO waves are a characteristic hallmark demarcating the onset of the transition period between quiet and active sleep (Ursin and Sterman, 1961). During transition, EEG wave activity shifts gradually from a synchronized to a desynchronized pattern, and EMG activity most notably disappears, designating atonia (Figs. $6 A, 7 A$ ). During the transition period, the spontaneous discharge rate of the entire population of DSCT neurons was $15.7 \pm 1.2$ spikes/s (range 1.6-40.1). However, during active sleep when EEG desynchrony, muscle atonia, PGO wave activity, and EOG activity are present, overall DSCT neuronal activity was reduced by $38.8 \%$ to $10.7 \pm 1.1$ spikes/s $(p$ $<0.05$, range 0.3-33.6). Individually, during active sleep 42 cells were suppressed by $>15 \%$ of their control value, 5 cells underwent $\mathrm{a} \geq 15 \%$ increase, and the remaining 3 cells were unchanged. The histogram illustrated in Figure 5 illustrates the distribution of these relative changes in spontaneous discharge across the entire group of DSCT neurons.

During the course of this study, we observed that DSCT neurons could be subclassified into two distinct categories based on the pattern of their active-sleep-related suppression of spike activity. Twenty-three of 50 cells (46\%) could be classified as type I cells, which demonstrated suppression that was sustained throughout the entire episode of active sleep. Figure $6 A$ illustrates a 15 min continuous recording of a type I DSCT neuron during quiet sleep, transition, active sleep, and re-awakening. In this particular cell, suppression of spike activity occurred during the transition into active sleep, just before the onset of atonia, and remained suppressed throughout the entire episode of active sleep. After re-awakening, the firing rate resumed to the preactive-sleep level. The histograms in Figure $6 B$ summarize the spike activity of 23 type I cells during sleep and wakefulness. Note that spike activity was suppressed during the transition period and throughout active sleep by 18.9 and $57.9 \%$, respectively $(p<0.05)$.

Nineteen of 50 DSCT cells ( $38 \%$ ) were subclassified as type II cells based on their overall pattern of active-sleep-related activity. In type II cells, the active-sleep-related suppression was not sustained as it was in type I cells but, rather, was intermittent in nature. An example of suppression of spike activity in a type II cell is illustrated in Figure $7 A$. In contrast to type I cells, which demonstrated reduced firing rates during transition and through- 
A

QS

EEG

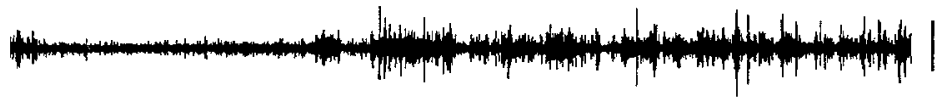

EOG

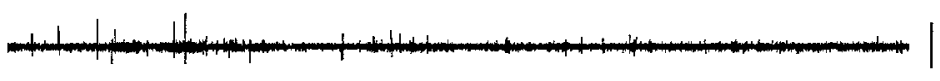

PGO

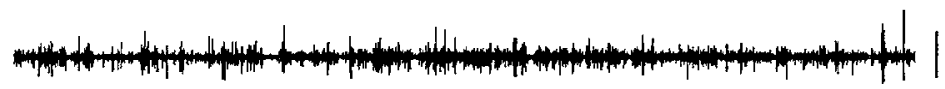

EMG
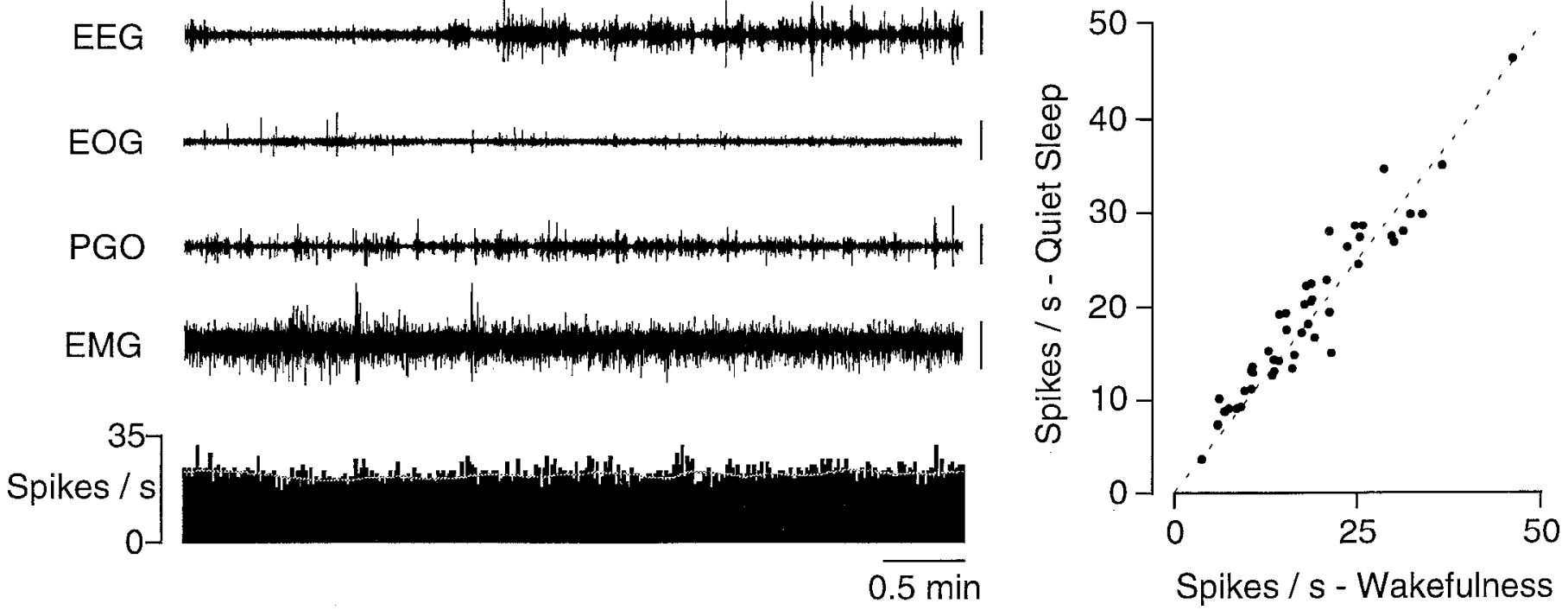

Figure 4. Continuous record of spike discharge activity of a DSCT neuron during the state of wakefulness ( $W$ ) and subsequent episode of quiet sleep $(Q S)$. The top four traces in $A$ represent behavioral statc as indicatcd by $E E G, E O G, P G O$, and $E M G$ activitics. The vertical calibration bars to the right of each trace correspond to $250 \mu \mathrm{V}$ for EEG, PGO, EMG, and $50 \mu \mathrm{V}$ for EOG activities. The bottom trace represents a rate meter output of spontaneous spike activity (binwidth, $1 \mathrm{sec}$ ) of an antidromically identified DSCT neuron. The firing rate of this cell was 25.3 and $26.7 \mathrm{spikes} / \mathrm{sec}$ during W and QS, respectively. A sliding average (binwidth, $30 \mathrm{sec}$ ) superimposed on the rate meter output (white line) indicates the stable baseline of spike activity for this cell across the states of W and QS. The scattergram in $B$ depicts the spike rate during W versus QS for all 50 DSCT neurons reported in the present study. Note that the points are in close apposition to the dotted line representing equivalent spike rates during W versus QS (correlation coefficient, $r=0.952$; $p<0.05$ ). The conduction velocity of the DSCT neuron in $A$ measured $83 \mathrm{~m} / \mathrm{sec}$

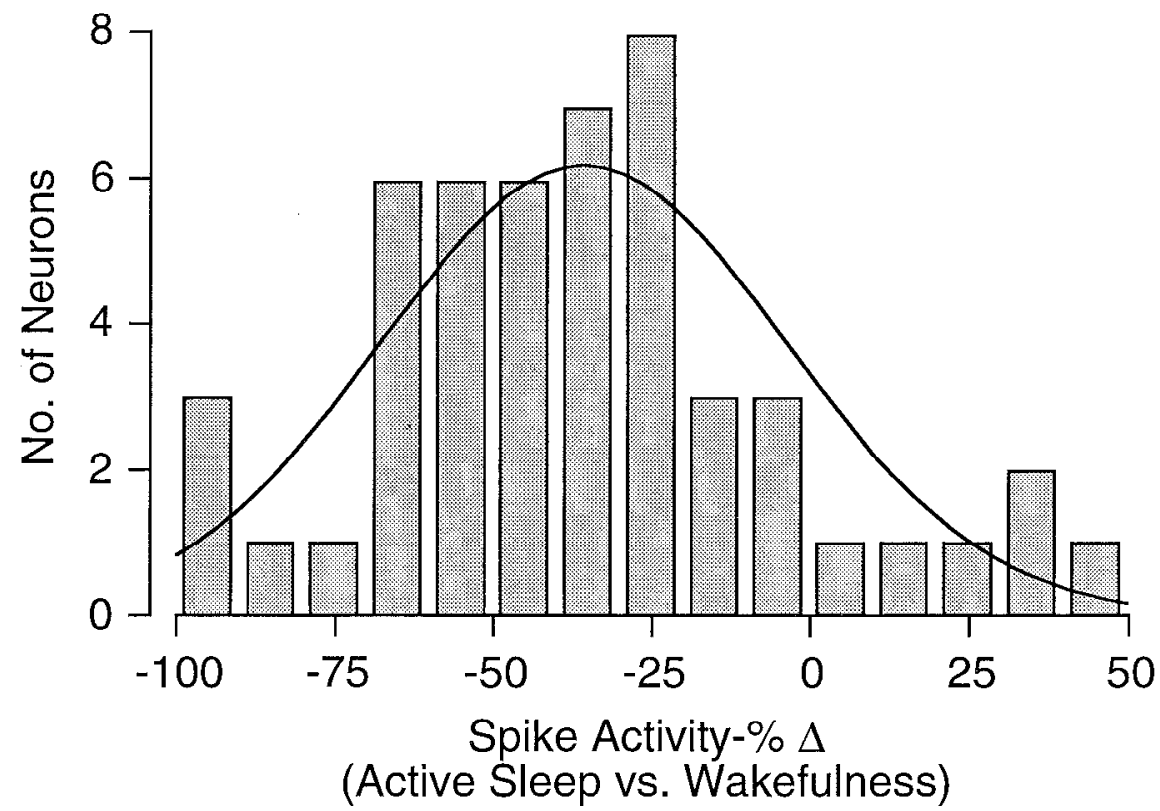

Figure 5. Histogram depicting the change in spontaneous spike activity of 50 Clarke's column DSCT neurons during the state of active sleep compared with wakefulness. Negative values on the abscissa indicate suppression; positive values represent facilitation. Note that the spontaneous discharge rate of a majority of DSCT neurons examined in the population was suppressed during active sleep. The curve indicates the distribution of these data around their mean. out the entire episode of active sleep, type II cells displayed phasic decreases only during active sleep.

The histograms in Figure $7 B$ summarize the rate data obtained for type II cells undergoing phasic periods of suppression during active sleep. The spike rate in type II cells decreased by $27.7 \%$ during active sleep $(p<0.05)$. This degree of active-sleep-related suppression was significantly different from that observed for type I DSCT neurons ( $p<0.05$, independent Student's $t$ test).

In both type I and II cells, the spike rate during the awake state after each episode of active sleep resumed to the level obtained during wakefulness preceding the transition and active-sleep periods (Fig. $6 B, 7 B$ ). Hence, the reduction in spike rate was activesleep-dependent. Eleven cells were recorded over two or more cycles of active sleep. In each case, type I $(n=5)$ and type II $(n$ $=6$ ) cells displayed their respective predictable patterns of suppression of spike activity; that is, type I cells underwent comparable degrees of sustained suppression, whereas type II cells underwent similar intermittent suppression. There was no statis- 

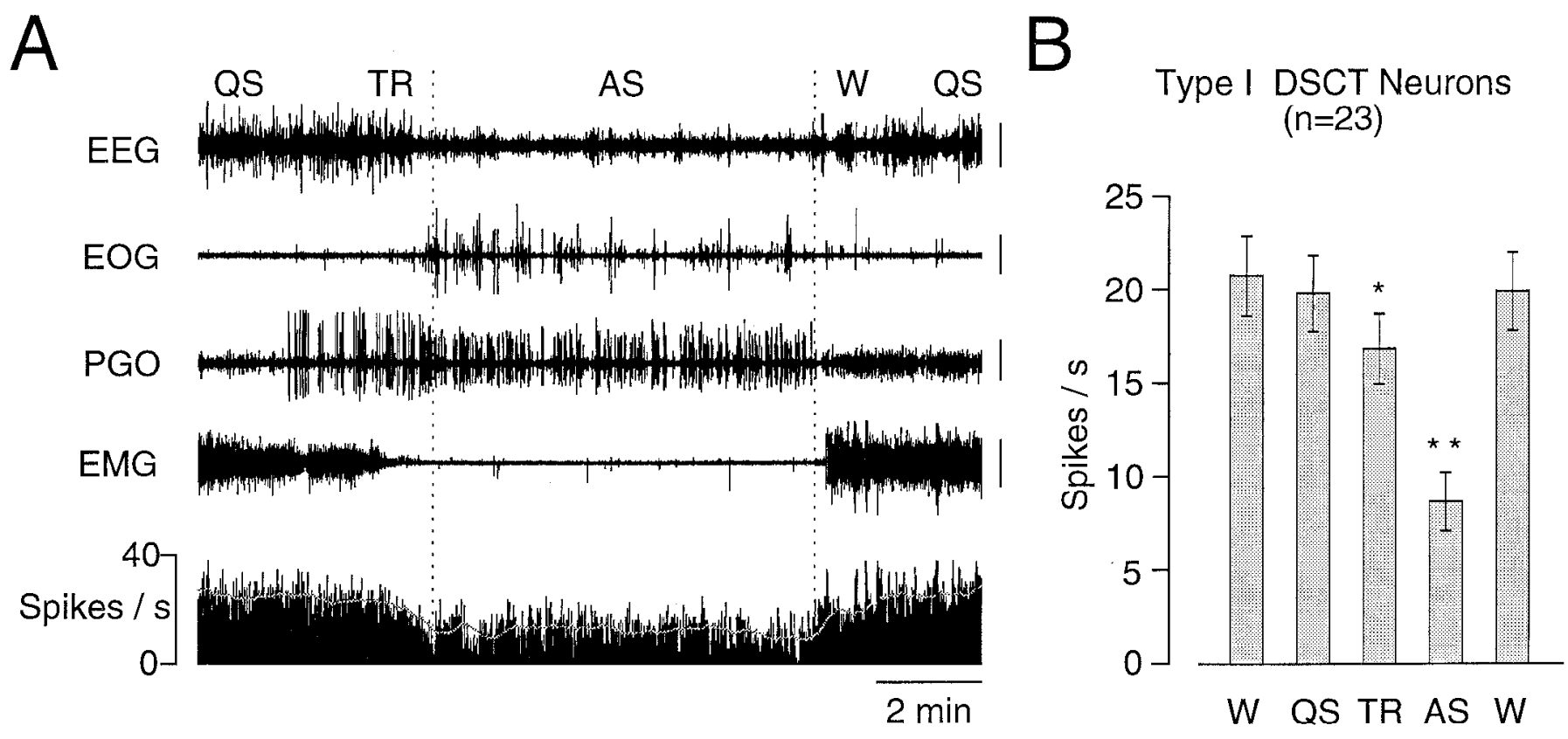

Figure 6. Continuous record of spontaneous spike activity of a type I DSCT neuron during the transition from quiet sleep to active sleep and subsequent episode of re-awakening. The top four traces in $A$ represent behavioral state as indicated in Figure $4 A$. The bottom trace represents a rate meter output of spontaneous spike activity (binwidth, $1 \mathrm{sec}$ ). The firing rate of this cell was 29.2 and 25.6 spikes/sec during wakefulness (not shown) and quiet sleep $(Q S)$, respectively. During the transition period $(T R)$, the cell's activity decreased by $31.3 \%$ to $20.2 \mathrm{spikes} / \mathrm{sec}$. Throughout the entire episode of active sleep $(A S)$, the cell's spike activity was decreased by $58.0 \%$ to $12.6 \mathrm{spikes} / \mathrm{sec}$. On re-awakening $(W)$, spike activity returned to pre-AS levels. The white sliding average (binwidth, $30 \mathrm{sec}$ ) is superimposed on the rate meter output, further highlighting the "tonicity" of the active-sleep-related suppression (dashed vertical lines) in this cell. The histograms in $B$ represent the group mean \pm SE of spontaneous activity of 23 type I neurons. Note that when compared with wakefulness, there was a $18.9 \%$ decrease in spike activity during the transition period and a $57.9 \%$ decrease during active sleep $(p<0.05$, ANOVA). The conduction velocity of the DSCT neuron in $A$ measured $78 \mathrm{~m} / \mathrm{sec}$.

tical difference in the average axonal conduction velocities between type I and type II cells (type I cells: $78.4 \pm 14.9 \mathrm{~m} / \mathrm{sec}$, range 47.9-104.4; type II cells: $80.5 \pm 13.5 \mathrm{~m} / \mathrm{sec}$, range $47.9-98.9 ; \rho>$ $0.05)$. In addition, there was no difference in the average spontaneous spike rate during the control state of wakefulness between type I and type II cells ( $p>0.05$; Figs. $6 B, 7 B$ ).

Finally, 5 of 50 DSCT neurons (10\%) displayed a $>15 \%$ increase in their spontaneous firing rate during active sleep compared with preceding episodes of wakefulness (wakefulness, $13.8 \pm 3.4$ spikes/ sec; active sleep, $17.8 \pm 4.4$ spikes/sec; $p<0.05$ ). Of these, 2 cells demonstrated a sustained increase, whereas the remaining 3 cells displayed intermittent periods of high-frequency bursts.

\section{Analyses of DSCT neuron interspike intervals during sleep and wakefulness}

ISIHs provide an indication of the regularity of spike discharge during a given behavioral state. Because a majority of the population of DSCT neurons underwent suppression during active sleep, interspike interval distributions were constructed for these cells using the same data files that were used for determining mean firing rates across the sleep-wake cycle.

The ISIHs for both type I and type II DSC'I cells during wakefulness and quiet sleep were very similar. Interspike interval distributions were leptokurtic and positively skewed, and a majority of interspike intervals ranged from 10 to $100 \mathrm{msec}$ (Fig. $8 A, B)$. The interval distributions for both types of DSCT neurons were characterized further during wakefulness and quiet sleep by similar median intervals and inner quartile ranges (Tables 1,2). These data and equivalent $\mathrm{CD}$ and $\mathrm{CV}$ values (Tables 1,2) substantiate the relative regularity of spike discharge of type $I$ and type II DSCT cells that comprise Clarke's column during these two behavioral states (Figs. $4 A, 8 A, B$ ).

The ISIHs of type I DSCT neurons during the state of active sleep were markedly different from ISIHs constructed from wakefulness and quiet sleep (Fig. $8 A$ ). Most notably, the ISIHs of individual type I cells during active sleep were characterized by a broader asymmetric distribution of interspike intervals and were made up of considerably fewer intervals. The asymmetrical nature of type I cell spike trains reflects an irregular pattern of spike discharge characterized by bursts of three to four action potentials followed by pauses of variable durations (Figs. 6A, 8A). The sustained reduction in firing rate also would contribute to a decreased number of longer interspike intervals. Consequently, the median interval value and inner quartile range during active sleep across all type I cells were extended twofold and fourfold, respectively (Table 1). An additional confirmation of this change in regularity of spike discharge is the sixfold and nearly twofold increase in the CD and CV values, respectively.

The ISIHs of type II DSCT cells during active sleep showed a similar distribution of intervals to those ISIHs constructed during preceding episodes of quiet sleep or wakefulness in that they displayed large peaks corresponding to shorter intervals. However, the distributions were characterized further by prolonged, positively skewed tails (Fig. 8B). This reflects a regularity in spike discharge as was observed during wakefulness and quiet sleep. In addition, the appearance of positively skewed tails in ISIHs of type II cells during active sleep indicates the presence of an underlying irregular pattern of spike discharge characterized, in part, by the presence of longer intervals attributable to pauses in 


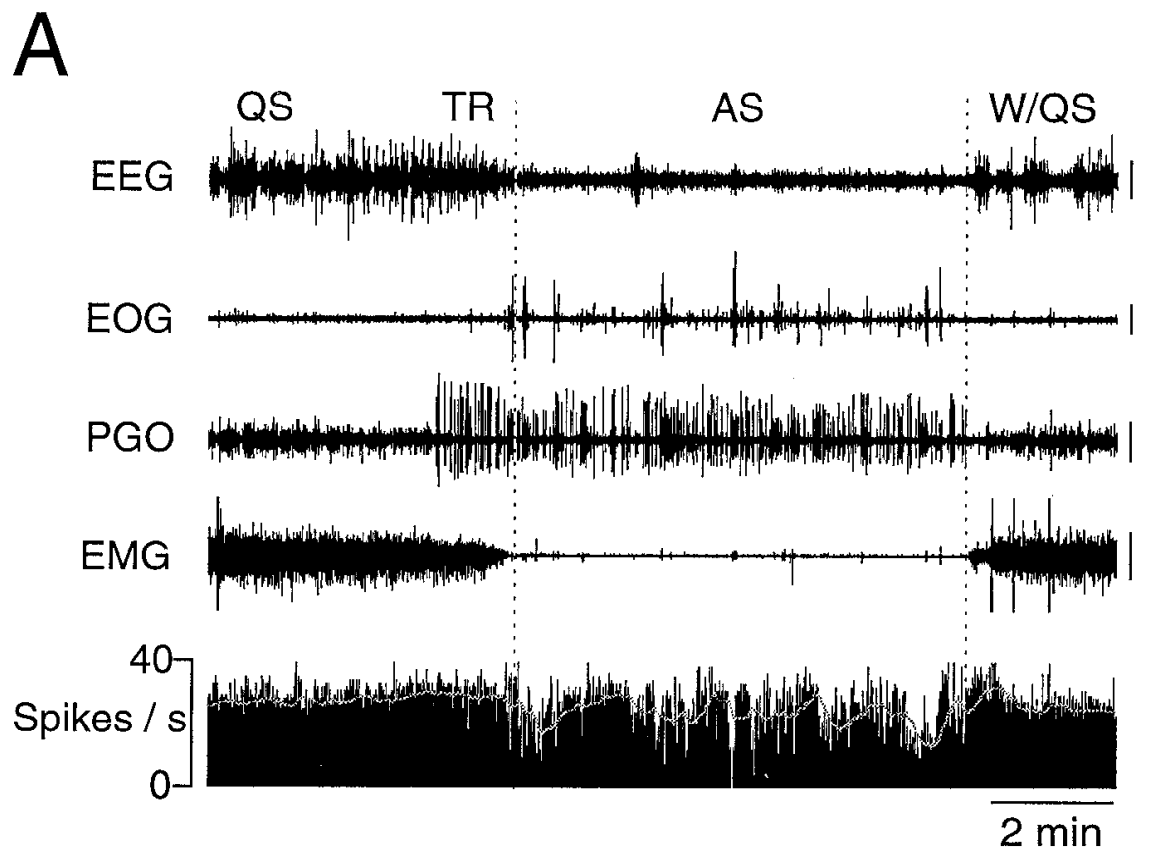

B
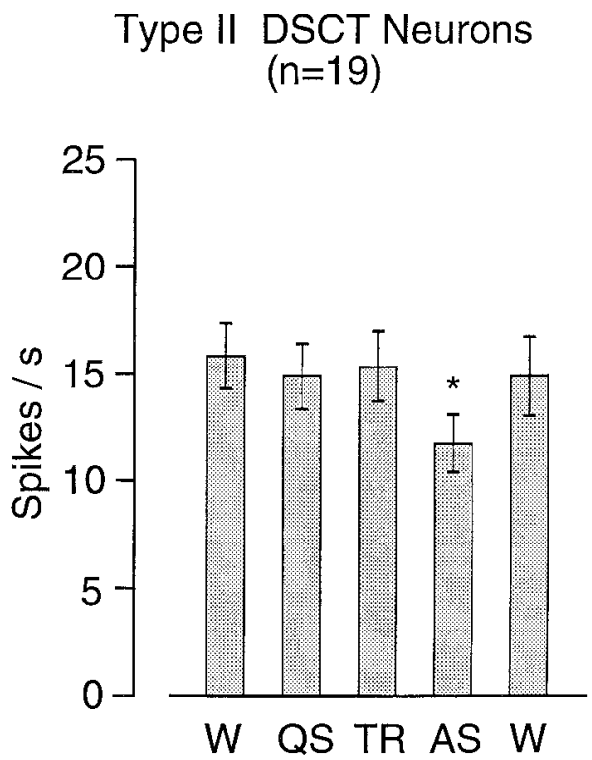

Figure 7. Continuous record of spike discharge activity of a type II DSCT neuron during the transition from quiet sleep to active sleep and subsequent re-awakening. The top four traces in $A$ represent behavioral state (see Figs. 4, 6). The vertical calibration bars to the right of each trace correspond to 250 $\mu \mathrm{V}$ for $E E G$ and $P G O$, and $100 \mu \mathrm{V}$ for $E O G$ and $E M G$ activities. The bottom trace in $A$ represents the rate meter output (binwidth, 1 sec). The firing rate of this cell underwent a phasic suppression only during the episode of active sleep $(A S)$ (dashed vertical lines) compared with quiet sleep ( $Q S$ ). On re-awakening $(W)$, spike activity returned to pre-AS levels. The white sliding average (binwidth, $30 \mathrm{sec}$ ) superimposed on the rate meter output further highlights the "phasic" nature of the active-sleep-related suppression in this cell; $T R$, transition period. The histograms in $B$ represent the group mean \pm SE of spontaneous activity of 19 type II neurons. Note that there was a $25.7 \%$ decrease in spike activity during active sleep compared with wakefulness $(p<0.05$, ANOVA; DSCT neuron $(A)$ conduction velocity, $94 \mathrm{~m} / \mathrm{sec})$

cell firing. Collectively, this was confirmed by the $\mathrm{CD}$ and $\mathrm{CV}$ values during active sleep being increased by factors of 6 and 1.8, respectively (Fig. 8B, Table 2).

\section{Suppression of ongoing activity during REM saccades of active sleep}

After closer examination, it was clear that pauses in cell firing were present in both type I and type II DSCT neurons during the REM cpisodes of activc slccp. Such pauscs werc most prominent during more intense and sustained REM saccades that also were associated with clustered PGO wave activity. An example of the REM-related pause of DSCT spike activity is presented in Figure $9 A$. During the active-sleep episode, six individual REM events occurred resembling that illustrated in Figure $9 A$. These REM events were marked at the beginning of the REM oscillation and PGO wave activity. The composite averaged peri-REM event histogram of activity derived from the six phasic individual REM episodes is illustrated in Figure $9 B$. Note that the spike activity in this cell was reduced maximally during the initial $2.5 \mathrm{sec}$ of the REM saccade. Detailed analyses of DSCT spike activity in association with eye movements during active sleep versus wakefulness will be reported elsewhere.

\section{DISCUSSION}

The present study was designed to explore the electrophysiological characteristics of neurons comprising a specific identified ascending lumbar sensory tract, namely, the DSCT, in the unanesthetized chronic behaving cat during the states of wakefulness, quiet sleep, and active sleep.
The positive identification of DSCT neurons in the chronic cat preparation was confirmed first by using classical antidromic identification criteria. The ongoing spike activity, as well as the monosynaptic responses evoked by low-intensity sciatic nerve stimulation, represents additional characteristic features that are common to DSCT cells in both acute anesthetized (Jansen et al., 1966; Mann, 1973; Oscarrson, 1973; Knox et al., 1977) and chronic (Soja et al., 1995b) animal preparations. Furthermore, the antidromic conduction velocities of DSCI neurons recorded from chronically instrumented cats are consistent with those reported for Clarkc's column DSCT ncurons in acutc ancsthetized preparations (Lundberg, 1964; Mann, 1973; Burke and Rudomin, 1977; Knox et al., 1977). Collectively, these findings, together with our retrograde labeling results using cholera toxin subunit B conjugated with colloidal gold, indicate that the backfired cells recorded likely were the large DSCT neurons of Clarke's column.

\section{Comparison of spontaneous discharge rates during wakefulness versus acute anesthetized state}

The spontaneous spike activity of DSCT neurons is thought to be attributable primarily to peripheral sources, i.e., group Ia and Ib fibers (Mann, 1973; Oscarsson, 1973; Burke and Rudomin, 1977; Bloedel and Courville, 1981; Walmsley, 1991). Central (interneuronal) and perhaps supraspinal sources also may contribute to the spontancous activity of DSCT ncurons (c.f. Holmqvist ct al., 1957, 1960). The question of whether intrinsic pacemaker activity contributes to the baseline activity of Clarke's column neurons has not yet been delineated clearly from intracellular studies. Autogenic synaptic feedback to Clarke's column DSCT neurons is 


\section{A Type I DSCT Neuron}

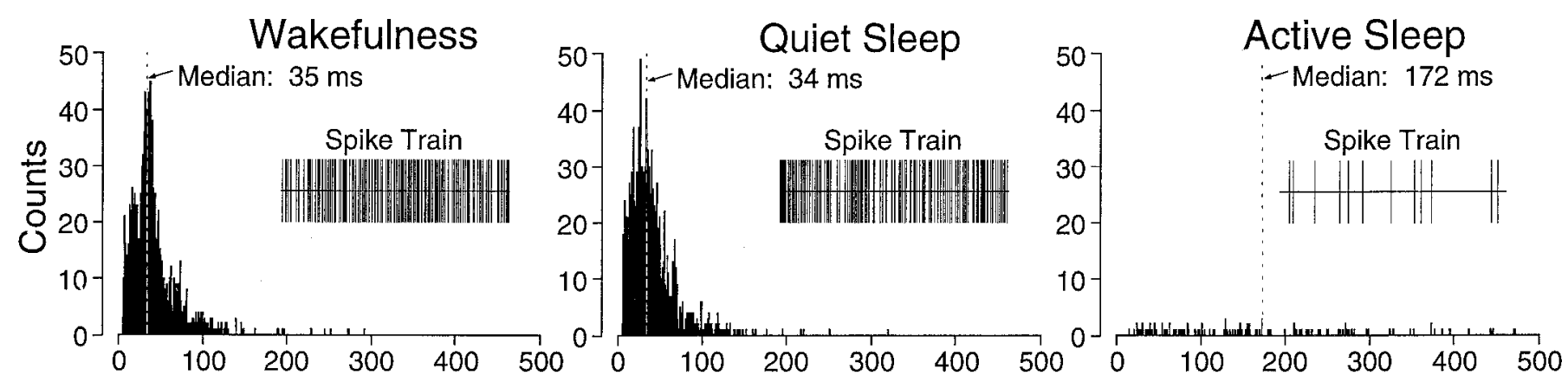

\section{B Type II DSCT Neuron}

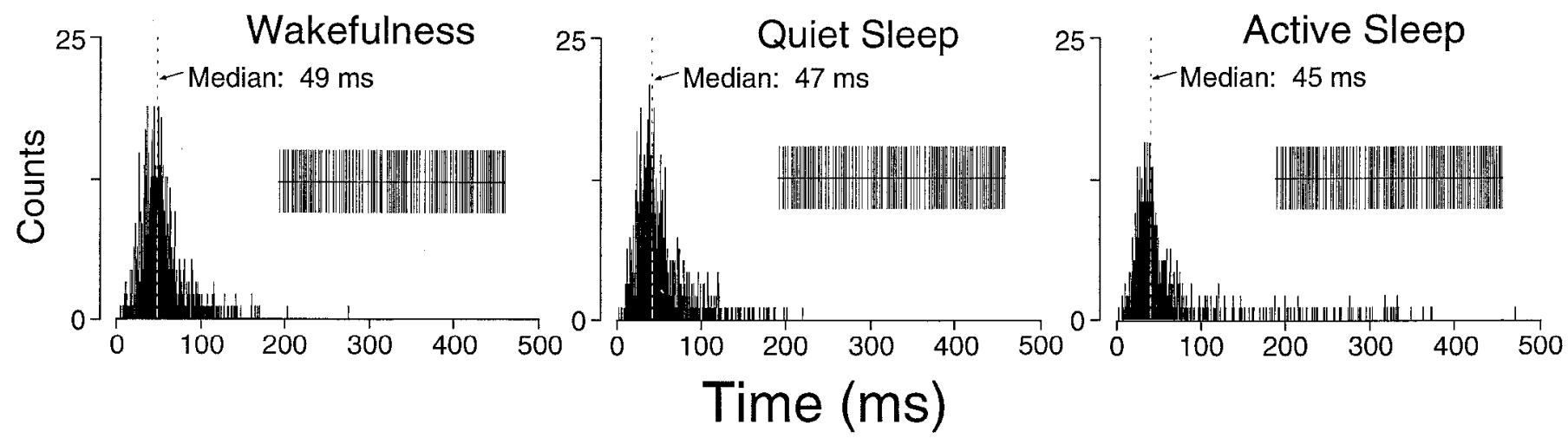

Figure 8. Representative ISIH distributions for spike activity recorded from type I $(A)$ and type II $(B)$ DSCT neurons recorded during wakefulness, quiet sleep, and active sleep. Note the similarity of the ISIH and computer-generated spike trains $(5 \mathrm{sec})$ of both neurons during wakefulness and quiet sleep. The median intervals are indicated by the dashed vertical lines. During wakefulness and quiet sleep, the median values correspond to the maximum peak envelope of short intervals. During active sleep, the ISII I of type I neurons often displayed a broader asymmetrical distribution of intervals, whereas ISIHs of type II neurons often were characterized by a smaller peak at short intervals followed by a long, skewed tail. Note the lower spike rate evident in the type I neuron during active sleep $(A)$ compared with the spike rate of the type II neuron $(B)$.

Table 1. Characteristics of interspike interval distributions of type I DSCT neurons during sleep and wakefulness $(n=23)$

Behavioral state

\begin{tabular}{|c|c|c|c|c|}
\hline \multirow{2}{*}{ Interval parameler } & \\
\hline & Wakefulness & Quiet sleep & Active sleep & Re-awakening \\
\hline Median (msec) & $\begin{array}{l}50.8 \pm 5.2 \\
(21.0-113.0)\end{array}$ & $\begin{array}{l}52.1 \pm 4.8 \\
(22.0-105.0)\end{array}$ & $\begin{array}{l}112.8 \pm 21.0 \\
(32.0-396.0)\end{array}$ & $\begin{array}{l}49.8 \pm 4.6 \\
(21.0-110.0)\end{array}$ \\
\hline Inner quartile range (msec) & $\begin{array}{l}50.4 \pm 9.1 \\
(10.1-191.0)\end{array}$ & $\begin{array}{l}45.6 \pm 7.8 \\
(5.3-139.0)\end{array}$ & $\begin{array}{l}211.8 \pm 50.3 \\
(11.6-839.0)\end{array}$ & $\begin{array}{l}50.5 \pm 8.4 \\
(8.8-167.0)\end{array}$ \\
\hline Coefficient of dispersion & $\begin{array}{l}0.04 \pm 0.01 \\
(0.002-0.17)\end{array}$ & $\begin{array}{l}0.04 \pm 0.11 \\
(0.002-0.23)\end{array}$ & $\begin{array}{l}0.24 \pm 0.04 \\
(0.005-0.68)\end{array}$ & $\begin{array}{l}0.08 \pm 0.03 \\
(0.003-0.19)\end{array}$ \\
\hline Coefficient of variation & $\begin{array}{l}0.64 \pm 0.05 \\
(0.25-1.19)\end{array}$ & $\begin{array}{l}0.66 \pm 0.05 \\
(0.20-1.29)\end{array}$ & $\begin{array}{l}1.14 \pm 0.08 \\
(0.37-1.96)\end{array}$ & $\begin{array}{l}0.68 \pm 0.06 \\
(0.19-1.39)\end{array}$ \\
\hline
\end{tabular}

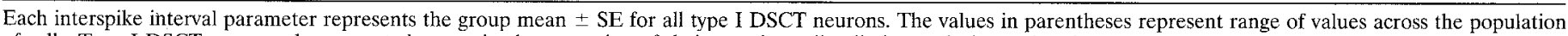
of cells. Type I DSCT neurons demonstrated a sustained suppression of their ongoing spike discharge during active sleep.

unlikcly to play a major role in underlying the spontaneous activity of these cells, because intracellular labeling studies of Clarke's column somata have not revealed the presence of recurrent axon collaterals (Randic et al., 1981; Houchin et al., 1983; Walmsley and Nicol, 1990).

Under our recording conditions, chronically instrumented cats are intact and unanesthetized, and their hindlimbs are tucked in a natural sitting position. During quiet wakefulness, in the absence of postural adjustments, the group mean firing rate of the entire population of DSCT neurons is $\sim 17$ spikes/sec, ranging from $\sim 4$ to 45 spikes $/ \mathrm{sec}$. The spontaneous spike rate for each individual DSCT cell is relatively constant (Fig. $4 A, B$ ) and is not related to its axonal conduction velocity.

All previous studies of Clarke's column DSCT neurons have 
Table 2. Characteristics of interspike interval distributions of type II DSCT neurons during sleep and wakefulness $(n=19)$

\begin{tabular}{|c|c|c|c|c|}
\hline \multirow[b]{2}{*}{ Interval parameter } & \multicolumn{4}{|c|}{ Behavioral state } \\
\hline & Wakefulness & Quiet sleep & Active sleep & Re-awakening \\
\hline Median (msec) & $\begin{array}{l}61.5 \pm 5.5 \\
(32.0-106.0)\end{array}$ & $\begin{array}{l}64.6 \pm 5.9 \\
(31.0-116.0)\end{array}$ & $\begin{array}{l}83.6 \pm 13.6 \\
(27.0-279.0)\end{array}$ & $\begin{array}{l}65.4 \pm 7.4 \\
(29.0-155.5)\end{array}$ \\
\hline Inner quartile range $(\mathrm{msec})$ & $\begin{array}{l}52.6 \pm 8.8 \\
(15.1-144.0)\end{array}$ & $\begin{array}{l}56.4 \pm 8.7 \\
(14.8-144.0)\end{array}$ & $\begin{array}{l}71.6 \pm 9.7 \\
(14.3-159.0)\end{array}$ & $\begin{array}{l}60.9 \pm 11.1 \\
(12.9-210.0)\end{array}$ \\
\hline Coefficient of dispersion & $\begin{array}{l}0.04 \pm 0.01 \\
(0.01-0.13)\end{array}$ & $\begin{array}{l}0.04 \pm 0.11 \\
(0.01-0.09)\end{array}$ & $\begin{array}{l}0.16 \pm 0.02 \\
(0.04-0.35)\end{array}$ & $\begin{array}{l}0.05 \pm 0.01 \\
(0.01-0.21)\end{array}$ \\
\hline Coefficient of variation & $\begin{array}{l}0.68 \pm 0.04 \\
(0.45-1.03)\end{array}$ & $\begin{array}{l}0.65 \pm 0.04 \\
(0.32-1.07)\end{array}$ & $\begin{array}{l}1.28 \pm 0.08 \\
(0.71-2.04)\end{array}$ & $\begin{array}{l}0.77 \pm 0.05 \\
(0.44-1.18)\end{array}$ \\
\hline
\end{tabular}

Each interspike interval parameter represents the group mean \pm SE for all type II DSCT neurons. The values in parentheses represent range of values across the population of cells. Type II DSCT neurons demonstrated phasic suppression of their ongoing spike discharge during active sleep
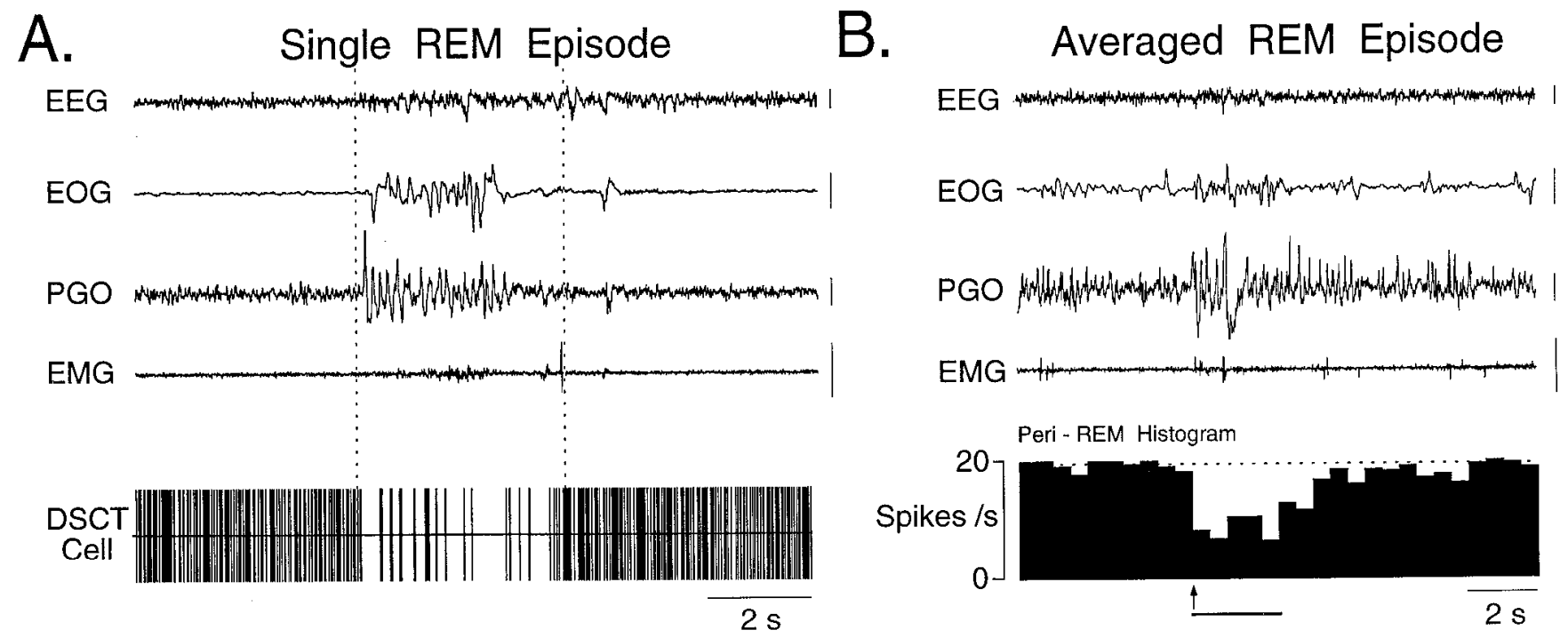

Figure 9. Suppression of type I DSCT neuronal spike activity during a phasic REM episode of active sleep. The top four traces in $A$ and $B$ represent behavioral state as indicated in Figures 4, 6, and 7. The vertical calibration har to the right of each trace corresponds to $500 \mu \mathrm{V}$ for $E E G$ and $E M G$, and $100 \mu \mathrm{V}$ for $E O G$ and $P G O$ activity, respectively. A typical REM episode during the state of active sleep is demarcated by the dashed vertical lines and is characterized by intense saccadic eye movements, a burst of PGO waves, and breakthrough activity in the isoelectric (neck) EMG trace. The bottom trace represents the computergencrated spikc train of spontancous spike activity of this cell around the REM event. The spike activity of this cell already was reduced during active sleep. Note the phasic suppression of this cell's spike activity during the REM event. The mean firing rate for this cell during a 4 sec period before, during, and after the REM event was $24.5,9.1$, and 28.8 spikes/sec, respectively. A total of six REM events of $\geq 2.5 \mathrm{sec}$ duration occurred during the active sleep episode for this cell. A cursor mark at the beginning of each event was used to trigger a computer subroutine for generating the averaged post-REM event histogram (binwidth, 1 $\mathrm{sec}$ ) of spike discharge as well as each behavioral state trace $(B)$. Note that the cell's firing rate in the averaged histogram was suppressed markedly during REM event by $56.4 \%$. The arrow indicates the onset of the events, and the dotted line under the histogram indicates a 2.5 sec duration common to all six phasic REM episodes throughout the state of active sleep (DSCT neuron conduction velocity, $101 \mathrm{~m} / \mathrm{sec}$ ).

been performed on cats anesthetized with barbiturates or other hypnotic agents, e.g., $\alpha$-chloralose. Group mean spontaneous firing rates for individual DSCT neurons in acute anesthetized cats generally are lower than those reported in the present study. For example, Holmqvist et al. (1957) reported that the group mean firing rates of 10 individual DSCT units was between $14 \mathrm{spikes} / \mathrm{sec}$ in one animal and 8 spikes/sec in another, whereas Laporte and Lundberg (1956), Mann (1973), and Knox et al. (1977) reported that firing rates of $\leq 10$ spikes/sec were very common in DSCT neurons.

It would be expected that the excitability of Clarke's column DSCT neurons as a population would be lower in the anesthetized state than in wakefulness. Indeed, in related work we have confirmed this by demonstrating that the spontaneous and evoked discharge responses of DSCT neurons are reduced markedly during the state of barbiturate anesthesia induced by thiopental compared with the state of wakefulness (Fragoso et al., 1995).

ISIHs indicate that DSCT spike discharge in the chronic cat during the states of wakefulness and quiet sleep is quite regular. Individual ISIHs in the present study during wakefulness and quiet sleep typically displayed a narrow range of short interspike intervals (Tables 1,2 ) that resemble those described for DSCT neurons recorded in acute anesthetized animal preparations (Jansen et al., 1966, 1969; Kuno et al., 1973; Mann, 1973). CD and 
CV values of interspike interval data from DSCT neurons recorded during wakefulness and quiet sleep also are consistent with those obtained from DSCT neurons in acute anesthetized preparations (Jansen et al., 1966, 1969; Knox et al., 1977).

\section{Suppression of DSCT neuron spike activity during active sleep}

The principal finding obtained in the present study is that the majority $(84 \%)$ of the population of DSCT neurons studied undergoes a reduction in its firing rate and a change in its spike train pattern specifically during the state of active sleep. Previous studies by Pompeiano et al. (1967), using mass-action recording techniques, suggested that during active sleep the transmission of ascending sensory information through the DSCT as well as other ascending pathways (Carli et al,, 1967a,b) is attenuated only during the phasic episodes of active sleep. Since the earlier pioneering studies by Carli et al. $(1967 \mathrm{~b}, \mathrm{c})$ and Pompeiano et al. (1967), no reports have appeared in the literature describing the activity of individual ascending lumbar sensory tract neurons during the sleep-wake cycle.

We have shown here that individual DSCT neurons indeed undergo a reduction in their ongoing firing rate during the state of active sleep. Two specific types of reduction in spike activity, i.e., sustained (type I) and intermittent (type II), also are evident. In addition, REM event-related pauses occur in DSCT spontaneous spike activity. The reduced rate and markedly different ISIHs of DSCT neurons during active sleep relative to quiet sleep and wakefulness indicate that complex changes occur in the transfer of ongoing sensory transmission to the cercbellum and higher centers during this state. This is confirmed by an active-sleep-related increase in the inner quartile range of interspike intervals and the increase in $C D$ and $C V$ values indicating increased spike aggregation (Cocatre-Zilgien and Delcomyn, 1992). Indeed, DSCT neuron spike trains during active sleep often displayed pauses followed by a bursts of three or more action potentials during non-REM (Fig. 8A) and REM (Fig. 9A) periods.

\section{Mechanism of active-sleep-related suppression of DSCT neurons}

The active-sleep-rclated suppression of DSCT neuronal spikc discharge observed in the present study may arise as a consequence of presynaptic and/or postsynaptic forms of inhibition (Carli et al., 1967a). However, a major limitation of the extracellular recording techniques used in the present study is that they do not allow one to distinguish between either mechanism operating on DSCT neurons. There is substantial evidence that during active sleep, lumbar motoneurons are subjected to a process of glycinemediated postsynaptic inhibition (Morales et al., 1987; Chase et al., 1989; Chase and Morales, 1990; Soja et al., 1991). Hence, the reduction of DSCT neuron aclivity during active sleep may reflect, in part, a process of disfacilitation arising because of the following: (1) a reduction of afferent input attributable to postsynaptic inhibition of motoneurons; (2) a reduction of muscle spindle sensitivity through the $\gamma$-loop (Kubota et al., 1967); and (3) a process of primary afferent depolarization that is engaged during active sleep (Morrison and Pompeiano, 1965, 1966; Baldissera et a1., 1966)

In preliminary expcriments (Soja et al., 1994), the probability of evoking antidromic action potentials with threshold stimuli was assessed during active sleep versus wakefulness in an effort to detect a postsynaptic shunt. However, this approach for detecting postsynaptic inhibition of DSCT cells during active sleep was complicated by the active-sleep-related reduction in spontaneous firing rate as well as by the high security for antidromic invasion inherent in DSCT neurons (Gustafsson and Lipski, 1980; Lipski, 1981).

A final possibility is that certain afferent inputs to Clarke's column DSCT neurons are subjected to active-sleep-specific modulatory influences. Presently, we have no information regarding which of our DSCT cells specifically belong to the proprioceptive or cutaneous divisions of the $\mathrm{DSC}^{-} \mathrm{I}$, but it is likely that wo recorded from DSCT cells receiving input from each of theso sources, because the ranges of conduction velocities for both categories overlap (Mann, 1971, 1973) with our conduction velocities, and the neuronal responses to low-intensity stimuli applied to the sciatic nerve include both short-latency and longer polysynaptic responses. Now that active-sleep-specific suppression of the ongoing discharge rate through Clarke's column DSCT neurons has been demonstrated clearly, it is important to determine whether there is active-sleep-dependent selectivity for certain types of afferent inputs, e.g., those specifically emanating from muscular versus cutaneous origins.

\section{Functional implications for suppression of Clarke's column DSCT neurons during active sleep}

An obvious consequence of the suppression of synaptic transmission through Clarke's column during active sleep is that the cerebellum is subjected to a reduction in afferent mossy-fiber input conveying lumbar proprioceptive and cutancous information. Paradoxically, the spontaneous firing rate of individual cerebellar Purkinje cells increases during the state of active sleep (Hobson and McCarley, 1972). The results presented here substantiate the claim advanced by Hobson and McCarley (1972) that the active-sleep-related increase in Purkinje cell excitability may have been attributable to enhanced synaptic inputs from reticulocerebellar, rather than spinocerebellar, pathways. Thus, certain cerebellar nuclei involved in executing fine motor commands that reccive afferent proprioceptive input from lumbar levels may not be engaged fully (or required) during active sleep. The additional reduction in synaptic transmission through Clarke's column to the cerebellum that occurs during the phasic REM episodes of active sleep also may contribute indirectly to the paroxysmal depolarizing influences directed to motoneurons during REM episodes (Chase and Morales, 1982, 1983; Soja et al., 1995c).

Another significant ramification that must be considered is the divergence that occurs with DSCT axons beyond the spinal cord level. The input conveyed by Clarke's column cells and other DSCT cells (Asif and Edgley, 1992) is known to reach prethalamic relay nuclei $Z$ and $X$ (Johansson and Silfvenius, 1977a,b) and the lateral reticular nucleus (Burton et al., 1971). Such medullary nuclei are thought to relay spinal proprioceptive and cutaneous inputs to the thalanus aud cortex, suggesting that sensory information transmitted via Clarke's column also is perceived consciously by higher centers. During active sleep, partial deafferentation to these centers would be expected to occur and might explain partially the diminished sensory awareness that is characteristic of the active-sleep state (Arkin et al., 1975; McCarley and Hoffman, 1981; Nielsen et al., 1993; Symons, 1993). In addition to the present findings, recent studies that support these clinically relevant observations indicate that the synaptic transmission through other sensory systems, e.g., the rostral trigeminal sensory nuclear complex (Cairns et al., 1995) and the spinoreticular, spinothalamic, and spinomesencephalic tracts (Soja et al., 1993), is attenuated in concert with the cessation of motor outflow during the state of active sleep. Whether a reduction of proprio- 
ceptive and exteroceptive input to the thalamus via other (un)crossed DSCT pathways originating from lower segments of the spinal cord (Anyama et al., 1973; Asif and Edgley, 1992; Huber et al., 1994) also occurs during active sleep remains to be determined.

\section{REFERENCES}

Aoyama M, Hongo T, Kudo N (1973) An uncrossed ascending tract originating from below Clarke's column and conveying group I impulses from the hindlimb muscles of the cat. Brain Res 62:237-241.

Arkin A, Sander KI, Ellman SJ, Antrobus J, Farber J, Nelson WT (1975) The rarity of pain sensation in sleep mentation reports. Sleep Res 4:179.

Armstrong-James M, Millar J (1979) Carbon fibre microelectrodes. J Neurosci Methods 1:279-287.

Asif M, Edgley SA (1992) Projections of group II-activated midlumbar spinocerebellar tract neurones to the region of nucleus $\mathrm{Z}$ in the cat. $\mathrm{J}$ Physiol (Lond) 448:565-578.

Baldissera F, Cesia-Bianchi MG, Mancia M (1966) Phasic events indicating presynaptic inhibition of primary afferents to the spinal cord during desynchronized sleep. J Neurophysiol 29:871-877.

Bloedel J, Courville J (1981) Cerebellar afferent systems. In: Handbook of physiology, Sec 1, The nervous system, Vol II, Motor control (Brooks VB, ed), pp 735-829. Bethesda: American Physiological Society.

Burke RE, Rudomin P (1977) Spinal neurons. In: Handbook of physiology, Sec I, The nervous system (Brookhart JM, Mountcastle VB, eds), pp 877-944. Bethesda: American Physiological Society.

Burton JE, Bloedel JR, Gregory RS (1971) Electrophysiological evidence for an input to lateral reticular nucleus form collaterals of dorsal spinocerebellar and cuneocerebellar fibers. J Neurophysiol 34:885-897.

Cairns BE, Fragoso MC, Soja PJ (1995) Activity of rostral trigeminal sensory neurons in the cat during wakefulness and sleep. J Neurophysiol 73:2486-2498

Carli G, Diete-Spiff K, Pompeiano O (1967a) Presynaptic and postsynaptic inhibition of transmission of somatic afferent volleys through the cuneate nucleus during sleep. Arch Ital Biol 105:52-82.

Carli G, Diete-Spiff K, Pompeiano O (1967b) Cerebellar responses evoked by somatic afferent volleys during sleep and waking. Arch Ital Biol 105:499-528.

Carli G, Kawamura H, Pompeiano O (1967c) Transmission of somatic sensory nerve volleys through ascending spinal hindlimb pathways during sleep and wakefulness. Pfiügers Arch 298:163-169.

Chase MH, Morales FR (1982) Phasic changes in motoneuron membrane potential during REM periods of active sleep. Neurosei Lett 34:177-182.

Chase MH, Morales FR (1983) Subthreshold excitatory activity and motoneuron discharge during REM periods of active sleep. Science 221:1195-1198.

Chase MH, Morales FR (1990) Atonia and myoclonia of active sleep. Annu Rev Psychol 41:557-584.

Chase MH, Soja PJ, Morales FR (1989) Evidence that glycinc mediates the postsynaptic potentials that inhibit lumbar motoneurons during the atonia of active sleep. J Neurosci 9:743-751.

Cocatre-Zilgien JH, Delcomyn F (1992) Identification of bursts in spike trains. J Neurosci Methods 41:19-30.

Eccles JC, Oscarsson O, Willis WD (1961) Synaptic action of group I and II afferent fibres of muscle on the cells of the dorsal spinocerebellar tract. J Physiol (Lond) 158:517-543.

Edgley SA, Gallimore CM (1988) The morphology and projections of dorsal horn spinocerebellar tract neurones in the cat. J Physiol (Lond) 397:99-111.

Edgley SA, Jankowska E (1987) Field potentials generated by group II muscle afferents in the middle lumbar segments of the cat spinal cord. J Physiol (Lond) 385:393-413.

Edgley SA, Jankowska E (1988) Information processed by dorsal horn spinocerebellar tract neurones in the cat. J Physiol (Lond) 397:81-97.

Fragoso M, Nixon G, Cairns BE, Soja PJ (1995) Barbiturate induced suppression of dorsal spinocerebellar tract (DSCT) neurons in the chronic cat. Soc Neurosci Abstr 21:1199.

Grant G, Xu Q (1988) Routes of entry into the cerebellum of spinocerebellar axons from the lower part of the spinal cord. Exp Brain Res 72:543-561.

Gustafsson B, Lipski J (1980) Effect of membrane polarization and synaptic activity on the timing of antidromic invasion. Brain Res 181:61-74.
Hobson JA, McCarley RW (1972) Spontaneous discharge rates of cat cerebellar Purkinje cells in sleep and waking. Electroencephalogr Clin Neurophysiol 33:457-469.

Holmqvist B, Lundberg A, Oscarsson O (1957) Functional organization of the dorsal spinocerebellar tract in the cat. V. Further experiments on convergence of excitatory and inhibitory actions. Acta Physiol Scand 38:76-90.

Holmqvist B, Lundberg A, Oscarsson O (1960) Supraspinal inhibitory control of transmission to three ascending spinal pathways influenced by the flexion reflex afferents. Arch Ital Biol 98:60-80.

Houchin J, Maxwell DJ, Fyffe REW, Brown AG (1983) Light and clectron microscopy of dorsal spinoccrebellar tract ncurons in the cat: an intracellular horseradish peroxidase study. Q J Exp Physiol 68:719-732.

Huber J, Grottel K, Celichowski J (1994) Dual projections of the ventromedial lamina VI and the medial lamina VII neurones in the second sacral spinal cord segment to the thalamus and the cerebellum in the cat. Neurosci Res 2:51-57.

Jansen JKS, Nicolaysen K, Rudjord T (1966) Discharge pattern of neurons of the dorsal spinocerebellar tract activated by static extension of primary endings of muscle spindles. J Neurophysiol 29:1061-1086.

Jansen JKS, Nicolaysen K, Walløe TL (1969) The firing of dorsal spinocerebellar tract neurones during inhibition. Acta Physiol Scand $77: 68-84$.

Johansson H, Silfvenius H (1977a) Axon-collateral activation by dorsal spinocerebellar tract tibres of group I relay cells of nucleus $\mathrm{Z}$ in the cat medulla oblongata. J Physiol (Lond) 265:341-369.

Johansson H, Silfvenius $H$ (1977b) Input from ipsilateral proprio- and exteroceptive hind limb afferents to nucleus $Z$ of the cat medulla oblongata. J Physiol (Lond) 265:371-393.

Knox CK, Kubota S, Poppele RE (1977) A determination of excitability changes in dorsal spinocerebellar tract neurons from spike train analysis. J Neurophysiol 40:626-646.

Kubota K, Tanaka R, Tsuzuki N (1967) Muscle spindle activity and natural sleep in the cat. Jpn J Physiol 17:613-626.

Kuno M, Munoz-Martinez EJ, Randic M (1973) Sensory inputs to neurones of Clarke's column from muscle, cutaneous and joint receptors. $\mathbf{J}$ Physiol (Lond) 228:327-342.

Laporte Y, Lundberg A (1956) Functional organization in the dorsal spinocerebellar tract in the cat. IV. Single fibre recording in Flechsig's fasciculus on adcquate stimulation of primary afferent neurons. Acta Physiol Scand 36:204 218.

Lipski J (1981) Antidromic activation of neurones as an analytic tool in the study of the central nervous system. J Neurosci Methods 4:1-32.

Lundberg A (1964) Ascending spinal hindlimb pathways in the cat. Prog Brain Res 12:135-163.

Mann MD (1971) Axons of dorsal spinocerebellar tract which respond to activity in cutaneous receptors. J Neurophysiol 34:1035-1050.

Mann MD (1973) Clarke's column and the dorsal spinocerebellar tract: a review. Brain Behav Evol 7:34-83.

Matsushita M, Hosoya Y, Ikeda M (1979) Anatomical organization of the spinocerebellar system of the cat as studied by retrograde transport of horseradish peroxidase. J Comp Neurol 184:81-106.

McCarley RW, Hoffman EA (1981) REM sleep dreams and the activation-synthesis hypothesis. Am J Psychiatry 138:904-912.

Morales FR, Boxer P, Chase MH (1987) Behavioral state specific inhibitory potentials impinge on cat lumbar motoneurons during active sleep. Exp Neurol 98:418-435.

Morrison AR, Pompeiano O (1965) Central depolarization of group la afferent fibers during desynchronized sleep. Arch Ital Biol 103:517-537.

Morrison AR, Pompeiano O (1966) Depolarization of central terminals of Group Ia muscle afferent fibres during desynchronized sleep. Nature 210:201-202.

Nielsen T, McGrcgor DL, Zadra A, Ilnicki D, Oucllet L (1993) Pain in dreams. Sleep 16:490-498.

Oscarsson O (1973) Functional organization of spinocerebellar paths. In: Handbook of sensory physiology, Vol II, Somatosensory system (Iggo A, ed), pp 339-380. Berlin: Springer.

Pompeiano O, Carli G, Kawamura H (1967) Transmission of sensory information through ascending spinal hindlimb pathways during sleep and wakefulness. Arch Ital Biol 105:529-572.

Randic M, Miltec V, Lowey AD (1981) A morphological study of cat dorsal spinocerebellar tract neurons after intracellular injection of horseradish peroxidase. J Comp Neurol 198:453-466. 
Soja PJ, Cairns BE, Fragoso M (1994) State-dependency and glycine sensitivity of dorsal spinocerebellar tract neurones in the unanesthetized cat. Can J Physiol Pharmacol 72[Suppl 1]:338.

Soja PJ, Fragoso MC, Cairns BE (1995a) Activity of dorsal spinocerebellar tract (DCST) neurons in the intact cat is decreased during active sleep. Sleep Res 24A:63.

Soja PJ, Fragoso MC, Cairns BE, Oka J-I (1995b) Dorsal spinocerebellar tract neuronal activity in the intact chronic cat. J Neurosci Methods 60:227-239.

Soja PJ, Lòpez-Rodríguez F, Morales FR, Chase MH (1995c) Effects of excitatory amino acid antagonists on the phasic depolarizing events that occur in lumbar motoneurons during REM periods of active sleep. J Neurosci 15:4068-4076.

Soja PJ, López-Rodríguez F, Morales FR, Chase MH (1991) The postsynaptic inhibitory control of lumbar motoneurons during the atonia of active sleep: effect of strychnine on motoneuron properties. $\mathrm{J}$ Neurosci 11:2804-2811.
Soja PJ, Oka J-I, Fragoso M (1993) Synaptic transmission through cat lumbar ascending sensory pathways is suppressed during active sleep. $\mathrm{J}$ Neurophysiol 70:1708-1712.

Symons D (1993) The stuff that dreams are not made of: why wake-state and dream-state sensory experiences differ. Cognition 47:181-217.

Ursin R, Sterman MB (1981) A manual for standardized scoring of sleep and waking states in the adult cat, pp 1-103. Los Angeles: University of California Brain Information Service, Brain Research Institute.

Walmsley B (1991) Central synaptic transmission: studies at the connection between primary afferent fibres and dorsal spinocerebellar tract (DSCT) neurones in Clarke's column of the spinal cord. Prog Neurobiol 36:391-423.

Walmsley B, Nicol MJ (1990) Location and morphology of dorsal spinocerebellar tract neurons that receive monosynaptic afferent input from ankle extensor muscles in cat hindlimb. J Neurophysiol 63:286-293. 